\title{
Racial Differences in Short-Run Earnings Stability and Implications for Credit Markets*
}

\author{
by \\ Raphael W. Bostic \\ Mail Stop 153 \\ Division of Research and Statistics \\ Board of Governors of the Federal Reserve System \\ Washington, DC 20551 \\ rbostic@frb.gov \\ Working Paper \\ June, 1997 \\ First version: July, 1996
}

JEL Classification: J31, G21, J71

Keywords: credit risk, race, earnings variance, mortgages

This paper examines the claim that observed racial differences in rejection rates for mortgage applications, which persist after controlling for many relevant factors, are due to racial differences in short-run earnings stability, which has not typically been included in empirical tests. The evidence does not support the proposition that blacks suffer from greater earnings instability than comparable whites, as few consistent significant differences between black and white earnings volatility are found. Only in the case of drastic earnings shocks with persistent effects does the possibility of significant racial differences reasonably remain. In general, racial differences in earnings instability appear to be minor and are unlikely to result in substantial differences in creditworthiness.

*The views expressed are the author's and do not represent the opinions of the Board of Governors of the Federal Reserve System or its staff. The author would like to thank Robert Avery, Paul Calem, Glenn Canner, Avner Grief, Roger Noll, John Quigley, John Shoven, Annika Sunden, Brian Surette, as well as seminar participants at American University. 
Recent evidence suggests that, after controlling for differences in levels of income and wealth, credit history, and employment experience, blacks fare worse in obtaining credit for home purchase loans than whites. Munnell et al. (1996) find that minority applicants for conventional home purchase mortgages are rejected $40 \%$ more frequently then white applicants, controlling for property, financial, and personal characteristics. One possible explanation for this disparity has been offerred by, among others, Benston (1995). He notes,

"blacks and other minorities might offer greater risk to lenders because past and present invidious discrimination and limited opportunities result in their having more uncertain income...Hence, they [banks and thrifts] might reject or discourage mortgage applications based entirely on considerations of risk that happen to be positively associated with the applicant's race." (p. 9)

The implication is that, due to differences in time profiles for income, blacks and whites with the same income, wealth, and experience levels, and even with similar credit histories, may represent different credit risks for lenders.

Moreover, evidence indicates that lenders may believe that racial differences exist in the propensity to default or prepay due to earnings instability. In their examination of possible racial differences in rejection rates for home mortgage applications, Munnell, et al. (1996) examine a large set of decision variables and find that only two factors - the total obligation ratio for the applicant and whether the applicant is self-employed - appear to vary significantly by race in their effect on the accept/reject decision (see Table 1). Both of these factors are proxies for risks associated with earnings uncertainty. The obligation ratio represents the degree to which a potential borrower is debt burdened and reflects to some degree the extent to which borrower decisions on loan repayment might be influenced by earnings shocks. Similarly, the selfemployed generally face more income uncertainty. The fact that these were the only decision factors found to significantly vary with race suggests that lenders' concerns with racial differences in earnings stability profiles may be quite real. ${ }^{1}$

If such propositions are accurate, then findings of racial differences in lending decisions may

\footnotetext{
${ }^{1}$ Similar effects were noted by Bostic (1996) and Hunter and Walker (1996).
} 
simply reflect these underlying relationships. Observed racial differentials might stem exclusively from individual differences in earnings instability or volatility, a characteristic that may be closely correlated with race. If true, then race could merely be proxying for earnings instability in models where direct measures of instability were omitted. To date, little evidence has been brought to bear on this issue.

This paper explores this issue by examining whether blacks have greater short run earnings volatility than comparable whites. Using recent data from the Panel Survey of Income Dynamics (PSID), I compare the short run earnings profiles of comparable whites and blacks from a sample of potential homebuyers. The evidence suggests few consistent significant differences between black and white earnings volatility. Only in the case of drastic earnings shocks with persistent effects does the possibility of significant racial differences reasonably remain. In general, racial differences in earnings instability appear to be minor and are unlikely to result in substantial differences in creditworthiness. The proposition that blacks suffer from greater earnings instability is therefore not supported by the data.

The paper is organized as follows. The first section discusses how earnings instability might affect lender assessments of credit risk. Sections II and III discuss the data and the empirical results, respectively. A final section presents conclusions.

\section{Earnings Instability and Credit Risk}

When a mortgage loan payment is due, a borrower has three options - pay the amount specified by the mortgage contract, default on the loan, or prepay the entire outstanding loan balance. $^{2}$ From a lender's perspective, default and prepayment are costly outcomes, since they reduce the net return on a loan. Since decreases in net return increase the riskiness of loans, factors that increase a borrower's probability of default or prepayment increase that borrower's riskiness.

Earnings instability affects the risk of offering credit by influencing borrower decisions of whether to default or to prepay, although the precise nature of this influence is complex and not

\footnotetext{
${ }^{2} \mathrm{~A}$ borrower may also prepay some of the outstanding principal without paying the entire outstanding amount. I ignore this possibility for ease of exposition.
} 
well understood. Volatility can be described by two measures: (i) the variance of earnings around its time trend, or (ii) drastic shocks that result in substantial increases or decreases in earnings. In both cases, there are two components to the risk associated with earnings instability. Downside risk, or $\sigma^{-}$risk, represents the probability of realizing a negative earnings change, while upside risk, or $\sigma^{+}$risk, captures the likelihood of a positive earnings change.

In the remainder of this section, I present a framework for how lenders might view the role of earnings instability in default and prepayment decisions. ${ }^{3}$ No formal model is presented. Rather, I emphasize general relationships to highlight some of the complexities associated with understanding the role that earnings instability plays in prepayment and default decisions.

The relationship between earnings instability and default from a lender's perspective is relatively straightforward. Increases in downside risk should unambiguously increase the likelihood of default. ${ }^{4}$ Conversely, upside risk should be negatively correlated with the likelihood of default by serving as a buffer against future negative shocks. Upside benefits also decrease the likelihood of default caused by expense-related shocks such as medical emergencies and natural disasters. ${ }^{5}$

To accurately describe the role that earnings instability plays in prepayment decisions, it is important to distinguish between two types of prepayment: refinancing and personally-motivated prepayment. Refinancing most often occurs when the current mortgage interest rate is sufficiently below the mortgage coupon rate that borrower savings from establishing a new mortgage contract exceed the costs associated with closing the existing account and establishing a new contract. ${ }^{6}$ Thus, interest rate movements and fee schedules determine whether refinancing is cost-effective for a borrower. Earnings volatility is relevant to the extent that it alters a homeowner's ability to qualify for the new loan. In theory, $\sigma^{+}$risk will be unrelated to the likelihood of refinancing since, in obtaining the initial mortgage, the homeowner has already demonstrated an ability to

\footnotetext{
${ }^{3}$ This discussion examines these relationships in a single period context, and thus does not consider dynamic effects that can influence the magnitude, though not the direction, of effects.

${ }^{4}$ Since earnings generally increase over time (Friedman, 1957; Gottschalk, 1982; Lillard and Willis, 1986), realized downside risk may not necessarily produce negative earnings shocks. In this case, default risk should increase less than in a static earnings environment.

${ }^{5}$ Though these occur relatively infrequently, the potential impacts may be substantial.

${ }^{6}$ Such costs include prepayment penalties, if any, and mortgage origination fees.
} 
qualify for a loan. However, $\sigma^{-}$risk will decrease the likelihood of a borrower qualifying for the new loan and thus should be negatively related to the probability of refinancing. On net, then, earnings instability is expected to be negatively related to the probability of refinancing.

Prepayments might also occur for personal reasons. At any given time, an individual might simply decide to move to another home. This decision might be based on a long-term investment strategy, such as upgrading from a small house to a larger one, or on short run considerations, such as changes in family status, the realization of improved job opportunities in a different locality, or job loss. Both $\sigma^{+}$and $\sigma^{-}$risk can induce such relocations -- $\sigma^{+}$risk by providing a better opportunity to move to a larger, more attractive home and $\sigma^{-}$risk by reducing the ability to cover current mortgage payments. Thus, earnings instability is likely to increase the likelihood of personally-motivated prepayment.

These relationships, with the implied net effects, are shown in Table 2. In the table, the signs represent effects associated with ceteris paribus increases in variation -- that is, increases in either upside or downside variation holding the other constant. In considering net effects, no assumptions on the variance distribution or relative magnitudes of effects are made, because these are unknown.

For defaults, the net effect of increases in earnings variation is unclear. This effect will depend on the nature of the increase in variance - whether it is skewed or symmetric - and the relative magnitudes of the two effects. In the case of prepayment, if refinancing is not feasible (i.e. the interest rate condition for refinancing is not satisfied), then increases in earnings variation unambiguously increase the likelihood of prepayment. However, if refinancing is feasible then the net effect will again be determined by the distribution of the variance and the relative magnitudes of the refinance and personal prepayment effects.

The key point here is that the relationship between earnings stability and credit risk is not straightforward. Depending on the distribution of the variability, the relative magnitude of effects, and market conditions, increases in earnings stability can increase or decrease the risk of default and prepayment. Thus, interpreting the effect of racial differences in earnings stability on racial differences in credit risk will depend critically on the precise nature of the variance differences and assumptions about the relative magnitudes of effects. 


\section{Data}

To empirically test for significant racial differences in earnings profiles, data on household earnings and individual characteristics of household heads were obtained from the Panel Survey of Income Dynamics (PSID) for all years between 1979 and 1988. Since the focus of this research is the effect of such instability on decisions to extend mortgages, the sample was constrained to include only black and white male households heads whose incomes made them likely to qualify for a mortgage. Also, we might expect that, for a number of reasons, lenders might consider applicants who are young, nearing retirement, or wealthy differently from the broader population. ${ }^{7}$ For this reason, the sample was further limited by age and income. To be included in the final sample, the household head had to be between 25 and 55 years old and have an income between $\$ 25,000$ and $\$ 80,000$. Variables for individual characteristics included in the sample, associated definitions, and selected sample statistics are listed in Appendix A.

Consistent with data from other sources, black household heads in the sample have lower average earnings, less full-time work experience, less education, are less likely to be selfemployed, and are more likely to be union members than white heads. ${ }^{8}$ As a test of the validity of the data, I estimated typical earnings functions for each year in the sample. The annual sample estimates (not shown) conform to the standard results in the literature. Increases in education, work experience, and job tenure all increase annual earnings, with college graduates and individuals with the highest levels of total full-time experience and job tenure having the highest earnings. Also, as is typically found, controlling for other factors, race has a significant negative effect on the level of annual earnings. Blacks earn 1 to 8 percent less than whites with identical years of education, work experience, tenure, and demographic profiles. ${ }^{9}$

Because most loans are short-lived (for example, mortgages are often on the books for no more than seven years), I examine earnings profiles over the short run, defined here as less than

\footnotetext{
${ }^{7}$ The creditworthiness of members of these groups may need to be evaluated based on different criteria from the population at large. Young applicants may be more likely to lack detailed credit histories, while applicants who are near retirement age are unlikely to receive salary income over the entire life of the mortgage. In these cases, other risk assessment factors may receive increased weight. Finally, high wealth levels might mitigate concerns about income and credit history.

${ }^{8}$ The Survey of Consumer Finances shows this relationship, as does the decennial Census.

${ }^{9}$ The annual earnings function estimates are available from the author upon request.
} 
five years. Two time spans, three years and five years, are considered in detail. This focus allows for numerous estimates using the ten years of data available. ${ }^{10}$ Relationships are estimated over all valid ranges in the data, resulting in a number of estimates of the quantities of interest. The discussion of results, therefore, focuses on persistent general relationships rather than on the magnitude of particular figures in any single calculation. All relationships highlighted in the text are robust across valid ranges within the 10 year time span. In addition, all analyses were run using a sample in which all observations were pooled. The pooled results, which are discussed in Appendix B, are qualitatively equivalent to the annual analyses.

\section{Analysis and Results}

Two aspects of earnings volatility are considered in this section. First, the profiles (i.e. the trend and variance) of earnings growth by race are compared. Although the focus of this research is largely on racial differences in earnings variability, it is important to also establish the facts regarding variation in general earnings trends. This is because earnings volatility will alter individual financial decisions only to the extent that the variance is large relative to the general earnings trend. Exclusively analyzing differences in earnings varability without considering underlying earning trends may therefore lead to inaccurate interpretations of results.

Second, racial differences in the incidence of significant shocks, positive and negative, are considered to determine whether blacks are more likely to experience large shocks that could induce prepayment or default. Conceivably, blacks may pose greater risks by this measure, even if profiles do not differ substantially. However, one-time shocks may not precipitate default or prepayment if the shock is quickly offset in subsequent time periods. I thus also search for significant racial differences in the persistence of earnings shocks.

\section{A. Comparing Earnings Profiles}

Trend. The first step in comparing earnings profiles is to determine whether significant differences exist in the general earnings trend over time. Table 3 indicates that, over all

\footnotetext{
${ }^{10}$ That is, many different 3- and 5-year spans within the data are appropriate for estimates. For example, 1979-1982, 1982-1985, and 1985-1988 are all valid time ranges for the 3-year case.
} 
intervals, whites have larger average earnings growth than blacks. However, since, on average, minorities differ from whites in levels of education, work experience, and other dimensions that could underlie the observed differences in earnings profiles, these factors must be controlled for explicitly. I therefore regress earnings changes on race and on individual characteristics thought to impact earnings and earnings growth, including education, employment experience, job tenure, marital status, and self-employment status. Accommodating the two time frames of interest, the estimated equations are

$$
\text { (1) } \quad P_{t+i}=\frac{Y_{t+i}-Y_{t}}{Y_{t}}=\beta_{1} X_{t}+\beta_{2} \text { Race }+\varepsilon_{t}
$$

where $P_{t+i}$ is the percentage difference in earnings at time $t$ and time $i, Y_{t}$ and $Y_{t+i}$ represent earnings in times $\mathrm{t}$ and $\mathrm{t}+\mathrm{i}, \mathrm{X}_{\mathrm{t}}$ is a vector of demographic characteristics at time $\mathrm{t}$, Race is a dummy variable indicating the race of the individual, $\beta_{1}$ and $\beta_{2}$ are parameter estimates, $i$ equals 3 or 5 depending on the span of interest, and $\varepsilon_{t}$ is the residual, or unexplained portion of the earnings shift. A significant negative (positive) coefficient on $\beta_{2}$ would suggest that blacks have significantly lower (higher) average earnings growth than comparable whites, which would generally be consistent with the proposition that blacks pose potentially greater credit risks.

The results of this estimation are also shown in Table 3. Over 3-year intervals, although blacks generally have lower average earnings growth (ranging from 15\% lower in 1980-83 to $88 \%$ lower in 1985-88 (not shown)), these differences are not statistically significant. The low level of significance for these estimates may be an artifact of the small sample sizes involved for particular intervals. As the sample size increases, statistical significance increases with few corresponding changes in the sign or magnitude of the coefficient estimates. For the 5-year intervals, point estimates for the race coefficients are again negative, and in two cases the estimates are statistically significant. For these two cases, the average growth for blacks is a substantial $67 \%$ and $88 \%$ lower than for comparable whites. In sum, after controlling for education, work experience, and other characteristics, blacks' short run average earnings growth appears to be less than that for whites and that, while often substantial, the gap varies from period to period. This is consistent with findings in other research, which has demonstrated that 
earnings profiles for blacks are not as steep as for comparable whites. ${ }^{11}$

Variance. Earnings variability can be examined in several ways. First, after dividing the sample by race, standard deviations of the distributions of raw earning changes can be computed and compared. This is done in Table 4. Whites have larger standard deviations than blacks. However, since whites also have a larger trends, the variation ratio, which divides the mean by the standard deviation, provides a better measure for comparing variability across races. The variation ratio for whites is generally higher than that for blacks, which suggests that whites have relatively lower earnings volatility.

However, since this comparison does not control for other factors, little can be said about the specific role that race plays in earnings instability using this method. A second technique isolates the role of race by comparing the distributions of the parts of earnings growth that can not be explained by other factors. The unexplained portion of earnings growth (or contraction) is obtained by regressing earnings changes on the same variables used in equation (1). Additionally, because the earnings profiles in the sample differ by race, the regressions are run separately by race. This assures that the appropriate mean (black or white) is used in calculating the different unexplained earnings shifts. The estimated equation is

$$
P_{t+i}=\frac{Y_{t+i}-Y_{t}}{Y_{t}}=\gamma_{1} X_{t}+\varepsilon_{i}
$$

Given the residual $\varepsilon_{t}$, I compute sample statistics measuring dispersion of $\frac{{ }^{\varepsilon} t}{P_{t+i}}$ to evaluate whether significant racial differences exist in the magnitudes and distributions of the unexplained portion of earnings shifts. $\frac{\varepsilon_{t}}{P_{t+i}}$ is considered because, since average earnings growth differs significantly by race, similar values of $\varepsilon_{\mathrm{t}}$ may represent different degrees of risk.

This procedure tests for whether, after controlling for variation in earnings due to other factors, there is additional variance in earnings dispersion associated with race. Note that earnings variance for each individual in the sample is not calculated. Rather, the approach generates estimates of the distribution of unexplained earnings deviations (in levels or percentages) three and five years after a given reference point for whites and blacks, controlling

\footnotetext{
${ }^{11}$ See Bound and Freeman (1992), among others.
} 
for other relevant variables. Dispersion, not individual variance, is measured. However, this method is appropriate in the context of lender decisions on creditworthiness because lenders are unlikely to know the earnings distribution of particular applicants; lenders will definitely observe the applicant's race when making decisions. Thus, from a lender's perspective, earnings dispersion by race and earnings instability by race will frequently be observationally equivalent. ${ }^{12}$ Table 5 compares $\frac{\varepsilon_{t}}{P_{t+i}}$ across races. The first two columns demonstrate that these residuals are an important component of overall growth. The mean residual exceeds 20 percent of overall growth for all but one interval and, in two cases, the residual is larger than total growth. Given these magnitudes, it is likely that unexplained, or random, earnings shocks do impact individual decisions and would affect prepayment or default decisions. Further, no clear racial patterns emerge. Neither blacks nor whites have consistently larger average residuals as a percentage of total earnings growth.

As evident in the table, whites tend to have larger standard deviations than blacks, which suggests that whites may have greater unexplained earnings instability than blacks. This is further verified using the variation ratio measure. Blacks have a higher ratio, corresponding to less dispersion, in 10 of the 12 cases. However, since this measure is sensitive to outliers, the interquartile range, computed as the difference between earnings changes at the 75 th and 25 th percentile of the sample population, is used as an alternate measure of dispersion. Using interquartile ranges, the observed relationship for standard deviations is reversed, with blacks having larger ranges than whites over nearly all of the intervals. So, apart from the extreme values in the distributions, blacks' unexplained earnings shocks are more disperse than whites' ceterus paribus, which is consistent with the notion that blacks' pose higher credit risks due to increased earnings instability.

Finally, since the mean of $\frac{{ }^{\varepsilon}}{P_{t+i}}$ is zero by definition, the relative skewness of the distributions can be assessed by directly comparing the earnings changes at various percentiles of the distribution. This is done in Tables 6 and 7. The top panels of the tables show the meanadjusted distributions of unexplained earnings shocks. From these panels, it appears that the

\footnotetext{
${ }^{12}$ An underlying assumption of this approach is that the observed distributions for these two years are representative of more general distributional patterns in the sample.
} 
distributions for both blacks and whites are skewed toward positive shocks; the distributions are not symmetric about the mean. ${ }^{13}$ This relation is stronger among blacks and over longer intervals. In the bottom panels of the tables, the white and black distributions are compared to directly test for whether blacks tend to have a more extreme unexplained earnings shock distribution than whites. Shaded regions show where the black distribution is more extreme. Over the two tables, only one strong relation emerges. The black sample's distribution is clearly more extreme for positive shocks over 5-year periods. Blacks have more extreme mean-adjusted values at 14 of the 20 percentile points examined. In none of the other three cases (negative shocks over 5-year periods and both shocks over 3-year intervals) is there a consistent racial pattern.

\section{B. Comparing the Incidences of Significant Earnings Shocks}

A second set of analyses defines earnings instability as the propensity to experience significant earnings shocks, either positive ("boons") or negative ("catastrophes"). Specifically, I consider whether, ceteris paribus, blacks experience higher incidences of catastrophes and boons. I create a dummy variable for either a catastrophe or boon, defined as an earnings change beyond some threshold level, and use a specification analagous to (1). For example, for the catastrophe analysis I estimate

$$
\text { Big }_{t+i}=F\left(X_{t}, \text { Race }\right)
$$

where $\operatorname{Big}_{\mathrm{t}+\mathrm{i}}=1$ if $\frac{Y_{t+k}-Y_{t}}{Y_{t}}, \mathrm{k}=1,2, . . \mathrm{i}$, is less than some threshold, $\mathrm{X}_{\mathrm{t}}$ again is a vector of characteristics at time $\mathrm{t}$, and Race is the individual's race. This specification defines a catastrophe as a large negative earnings shock in any year over the time interval. To verify the robustness of the observed relations, I use four different thresholds -- 10, 25, 35, and 50 percent -- to define a catastrophe. Since the dependent variable is discrete and binary, equations (3) are estimated via probits. The same procedure is used to analyze the relation between race and boons, the only

\footnotetext{
${ }^{13}$ If the distributions were symmetric, the 50th percentile would be close to zero. In only 4 of the 24 cases is the 50th percentile within 10 percent of the mean.
} 
difference being that $\mathrm{Big}_{\mathrm{t}+\mathrm{i}}=1$ if $\frac{Y_{t+k}-Y_{t}}{Y_{t}}$ is greater than the threshold, which is positive in this case. Positive regression coefficients on race from these estimates would indicate that minorities were more likely to experience earnings catastrophes or boons over the particular short run interval. Like the analysis for earnings variance, this procedure explicitly accounts for racial differences in the distribution of individual characteristics and thus provides a test of the hypothesis that, holding all else equal, minorities represent a higher credit risk due to this type of earnings instability.

Table 8 shows the results of estimating equation (3) for catastrophes and boons. Blacks are more likely to experience earnings catastrophes; point estimates of the effect of race on the incidence of catastrophes are positive in nearly every 3-year and 5-year interval examined. However, the relationship is uneven, as racial differences are statistically significant for some intervals but not for others. Significant racial differences are observed roughly between 1982 and 1988. In every 3-year interval between 1983 and 1988, blacks were much more likely to experience catastrophes at every threshold level. These differences ranged from 33 percent to 100 percent.

A different relationship is observed in looking at large positive earnings shocks. Holding other factors constant, blacks are generally less likely to have large increases in short run earnings, as coefficient estimates are predominantly negative. However, like the catastrophe case, the relation is generally not statistically significant. Interestingly, the negative relation between race and boon incidence weakens as the time span is shortened and as the threshold is raised. At each threshold level, a smaller percentage of the 3-year estimates are negative relative to the 5-year estimates. Further, the number of negative estimates falls as the threshold is raised. In fact, over 3-year intervals at the two higher threshold levels, the relationship between race and boon incidence appears to be positive (10 positive estimates out of 14).

As noted earlier, racial differences in the likelihood of ever experiencing a catastrophe or boon may not translate into racial differences in the likelihood to default or prepay. One-time shocks may not precipitate default or prepayment if the shock is quickly offset in subsequent time periods. Rather, it may be persistent large earnings shocks that are more relevant for default and prepayment decisions. If so, then racial differences in credit risk will be represented by racial differences in average earnings changes. 
To test for such differences, I use $\mathrm{A}_{\mathrm{t}}=\frac{\frac{1}{i} \sum_{\mathrm{n}=1}^{\mathrm{i}} \mathrm{Y}_{\mathrm{t}+\mathrm{n}}-\mathrm{Y}_{\mathrm{t}}}{\mathrm{Y}_{\mathrm{t}}}, i=3,5$, which is the average earnings growth (or contraction) for an indiviual over the relevant time period, as a focus rather than $\frac{Y_{t+k}-Y_{t}}{Y_{t}}, i=1,2, \ldots$, i. Equations (1) and (3) are rerun using this new dependent variable. The proposition tested in the new estimate of equation (1) is whether, after controlling for other factors, blacks have lower average earnings growth. As is shown in Table 9, the race coefficients indicate that this is generally the case, although differences are not generally statistically significant. A number of variations on this test were also run to examine whether racial differences in the persistence of drastic earnings shocks were important for particular subgroups in the sample. Equation (1) was reestimated for subsamples including (i) only those with negative $A_{t}$, (ii) only those with positive $A_{\mathfrak{v}}$ (iii) only those who had experienced an earnings catastrophe over the relevant interval, and (iv) only those who had experienced an earnings boon over the relevant interval. The same basic result, that racial differences are insignificant, was obtained in all four cases.

Since $A_{t}$ represents average annual growth over the period, the reestimated equation (3) tests for the existence of racial differences in the persistence of drastic shocks. The results, shown in Table 10, mirror those for the incidence of shocks. Blacks are more likely to have a persistent negative shock and less likely to experience a positive shock, but the correlations in both cases are not generally statistically significant. As in the incidence case, the only racial effect observed was for the persistence of catastrophes over the 3- and 5-year intervals that began in 1982 and 1983. In these four intervals, blacks had significantly higher likelihoods of experiencing a persistent negative shock in 14 of the 16 cases examined. It appears that, starting in 1982, black potential homeowners were more susceptible to persistent short run drastic earnings shocks than comparable whites. Determining the origins of this interesting result would be a worthy pursuit.

\section{Conclusion: Are Blacks Riskier?}

It has been hypothesized that blacks may pose higher risks of default and prepayment than comparable whites due to systematic differences in short run earnings experiences, either through higher short run variance in earnings or increased incidence of drastic earnings shocks. Further, there is evidence that lender behavior may reflect such beliefs.

In the preceding section, the earnings profiles of whites and blacks were compared to address 
this issue. The evidence from Section A suggests that the black sample demonstrates an overall earnings stability that is similar to that of the white sample. Blacks have greater unconditional variabiliy (Table 4), but this relation virtually disappears after controlling for other factors. Section B estimates show few consistent statistically significant racial differences in the incidence or persistence of drastic negative or positive earnings shocks. However, an "era" effect was observed, as blacks were found to be more susceptible to persistent negative catastrophes over the latter years of the sample period.

With regard to the relationship between earnings instability to credit risk, the results offer strongly suggestive, though not completely conclusive, answers. If variance around the short-run trend is used as the measure of instability, there is little evidence to suggest that black potential applicants pose a greater risk than comparable whites. The variability is basically the same for these two groups. By contrast, the results from the analysis of drastic earnings shocks imply that, at least for some years, the earnings variance for blacks is more skewed toward negative outcomes than it is for comparable whites. This is analogous to increasing only the downside risk associated with earnings variance, and implies a higher probability of default for black applicants. This result is consistent with findings in other research. ${ }^{14}$ Regarding prepayment, the implied relation is ambiguous.

The results for drastic earnings shocks are not universal, however. For more than half of the sample period, no significant racial differences in the likelihood of an earnings catastrophe were observed. Further, when considering the persistent effects of these catastrophes, significant effects were consistently observed only for intervals beginning in 1982 or 1983. Thus, in both analytical cases (short run variance and drastic earnings changes) the evidence suggests that the strong form of the original thesis -- that, among potential homebuyers, blacks are inherently riskier than comparable whites due to differences in earnings variability -- can be refuted.

The persistence results also suggest that the existence of racial differences in earnings variance may be tied to broader economic trends. For example, evidence from previous research has found that black males fared relatively worse economically during the mid-1980's, precisely

\footnotetext{
${ }^{14}$ Berkovec, Canner, Gabriel, and Hannan (1994) find that, among FHA-insured residential mortgages, black borrowers were more likely to default than comparable white borrowers.
} 
the period when significant differences are observed in this study. ${ }^{15}$ However, observed significant differences appear to be temporary, at least over 3-year intervals, and not reflective of a fundamental shift in the relation between race and catastrophic earnings events. Such a conclusion cannot be made for five-year periods with this dataset. Only additional data on 5-year effects beyond 1988 can definitively address this question.

These results directly contradict conventional notions that black applicants are inherently riskier than comparable whites for earnings volatility-related reasons. ${ }^{16}$ Given that lenders may hold conventional notions regarding earnings instability and act on such ideas, such countervailing information can be important for changing risk assessment and credit allocation policies by lenders. In particular, such changes could result in an expansion of mortgage credit afforded to minorities and a more efficient allocation of credit resources generally.

Finally, while a majority of this discussion has been couched in terms of mortgage lending, it is important to emphasize that the results have implications for credit markets generally. This paper has examined a relevant issue associated with assessing general credit risk, regardless of the form of the credit involved. Given the results, differences in earnings stability would not appear to be a source of much racial variation in creditworthiness; earnings variance should be considered similar for all applicants in all credit markets.

\footnotetext{
${ }^{15}$ For example, using Current Population Survey data, Bound and Freeman (1992) show that the racial wage gap for young males increased dramatically in 1982 and peaked in 1985 (figure I, p. 205).

${ }^{16}$ Additional analyses on racial differences in the incidence of "triggering events," discussed in Appendix $\mathrm{C}$, further corroborates these findings.
} 


\section{Appendix A: Variables used in Estimates and Selected Sample Statistics}

\begin{tabular}{|c|c|c|c|}
\hline \multirow[b]{2}{*}{ Variable (Statistic) } & \multirow[b]{2}{*}{$\begin{array}{l}\text { Definition if included in Estimates: } \\
\qquad=1 \text { if head has }\end{array}$} & \multicolumn{2}{|c|}{ Statistic: } \\
\hline & & White Sample & Black Sample \\
\hline Income $(\$)$ & & 36299 & 32017 \\
\hline Experience (Yrs.) & & 22 & 21 \\
\hline 0-5 (Pct.) & <omitted variable> & 2.1 & 1.2 \\
\hline 6-10 (Pct.) & total full-time experience of $6-10$ years & 9.2 & 8 \\
\hline 11-15 (Pct.) & total full-time experience of $11-15$ years & 16.5 & 23.9 \\
\hline 16-20 (Pct.) & total full-time experience of $16-20$ years & 19 & 26.6 \\
\hline 21-25 (Pct.) & total full-time experience of $21-25$ years & 16.2 & 11.1 \\
\hline $25+($ Pct. $)$ & total full-time experience of $25+$ years & 36.9 & 29.2 \\
\hline Tenure (Yrs.) & & 10.2 & 11.4 \\
\hline 0-5 (Pct.) & <omitted variable> & 38.3 & 23.9 \\
\hline 6-10 (Pct.) & current job tenure of $6-10$ years & 19.8 & 28 \\
\hline $11-15$ (Pct.) & current job tenure of $11-15$ years & 16.8 & 22.3 \\
\hline 16-20 (Pct.) & current job tenure of $16-20$ years & 12.3 & 15.7 \\
\hline 21-25 (Pct.) & current job tenure of $21-25$ years & 8 & 3.4 \\
\hline $25+($ Pct. $)$ & current job tenure of $25+$ years & 6.7 & 7.9 \\
\hline Dropout (Pct.) & less than 8 years of education & 1.9 & 6.3 \\
\hline High School (Pct.) & $8-12$ years of education & 33.1 & 43.5 \\
\hline College (Pct.) & $12+$ years of education <omitted variable> & 65 & 50.1 \\
\hline Union (Pct.) & union membership & 23 & 52.3 \\
\hline Self-empl. (Pct.) & own business & 10.7 & 1.3 \\
\hline Married (Pct.) & spouse & 87.3 & 82.9 \\
\hline Children (Avg. Num.) & & 1.3 & 1.4 \\
\hline Region 1 & primary residence in Northeast & & \\
\hline Region 2 & primary residence in North-Central & & \\
\hline Region 3 & primary residence in South & & \\
\hline Region 4 & primary residence in West <omitted var.> & & \\
\hline
\end{tabular}




\section{Appendix B. Estimates Using a Pooled Sample}

The individual 3-year and 5-year samples were also pooled to create larger 3-year and 5-year datasets. ${ }^{17}$ Given the variation in results across particular individuals, estimates using these pooled samples could offer a clearer picture of whether racial effects exist. Because a single individual might represent several observations in the pooled sample, individual fixed effects must be included in regression estimates. However, because race does not change over time, it is perfectly collinear with the fixed effects -- both can not be estimated simultaneously. Thus, estimates are obtained using only the fixed effects, the residuals of these estimates are averaged across races, and t-tests are used to establish if there are significant racial differences between these residuals. Unfortunately, this procedure yielded very small residuals which were difficult to interpret intuitively. The main text therefore emphasizes the cross-sectional estimates.

The results using the pooled sample mirrored those for individual time intervals. Blacks had lower unconditional average earnings growth and higher unconditional variance than whites. However, after controlling for personal differences, racial differences in trend were not significant. For the drastic shock analyses, data limitations precluded the inclusion of fixed effects in the probit in equation (3). Instead, a linear probability model including fixed effects was estimated. As in the trend and variance analysis, pooled results mirrored those for the individual intervals. Although, blacks were found to be less likely to experience earnings boons and more likely to experience an earnings catastrophe, neither of these differences was large or statistically significant. Results tables for the pooled analyses are available upon request.

\footnotetext{
${ }^{17}$ For example, in the 5-year pooled sample, the 1979-84, 1980-85, 1981-86, 1982-87, and
} 1983-88 datasets are stacked to create one large dataset. 


\section{Appendix C. Trigger Events}

The main result -- that, among potential homebuyers, few racial differences in earnings variance exist -- runs counter to conventional wisdom as well as against some publicly documented trends regarding the incidence of many events thought to trigger earnings instability. For example, aggregate statistics show that black households have higher rates of divorce than white households. ${ }^{18}$ Additionally, research has found that minorities are often more likely to experience job loss. ${ }^{19}$ Also, far more black families are single-parent households, which are far more vulnerable to trigger events than households in which both parents are present. The PSID offers an opportunity to compare the incidence of selected trigger events to determine whether the restricted sample used in the study conforms to broader trends. Table C.1 shows the incidence of various "trigger events" by race over various 1-year, 3-year, and 5-year intervals between 1979 and 1985. Figures are included both for the restricted sample used in this study and a sample with no earnings restrictions.

Looking first at the restricted sample (columns 3 and 4), compared to whites, blacks appear more likely to become married, but slightly less likely to become divorced. Thus, if marriage is a stabilizing factor, the black population in our restricted sample has a higher propensity for stability relative to the white population. In examining differences in changes in work status, blacks tend to be more likely to have large increases and large decreases in hours worked. These two offsetting effects will reduce observed average racial differences. Perhaps most importantly, however, the percentages are all quite similar. Order of magnitude differences in the incidence of divorce, marriage, or job status changes across the races are not observed. So even for triggering events, the populations are more similar than different.

In trying to reconcile this with conventional wisdom, the unrestricted and restricted samples were compared. The unrestricted sample shows a higher incidence of trigger events, as marriage, divorce, and large work hour changes are more common. However, the relative incidence of negative trigger events (divorce and a large decrease in work hours) among blacks compared to

\footnotetext{
${ }^{18}$ For example, the Current Population Survey indicates that divorce rates among blacks were slightly higher than among blacks in the 1990s (7.9 percent versus 7.5 percent in 1995 and 8.1 percent versus 6.8 percent in 1990).

${ }^{19}$ See, for example, Ong and Lawrence (1995).
} 
whites is greater in the unrestricted sample. No analogous relation is observed for positive triggers. Thus, the unrestricted sample would appear to conform to the conventional wisdom. In sum, the population of potential homebuyers is qualitatively different, and far less susceptible to trigger events, than the population overall. 
Table C.1. Comparison of Selected Experiences by Race over the Sample Period

\begin{tabular}{|c|c|c|c|c|c|}
\hline \multirow[b]{2}{*}{ Interval } & \multirow[b]{2}{*}{ Variable } & \multicolumn{2}{|c|}{ Unrestricted } & \multicolumn{2}{|c|}{ Restricted } \\
\hline & & White & Black & White & Black \\
\hline \multirow[t]{7}{*}{$\overline{1979-80}$} & Pct. moved in past year & 17.6 & 18.9 & 14.3 & 17.5 \\
\hline & Pct. with marital changes & & & & \\
\hline & Married & 1.7 & 2.0 & 1.8 & 0.0 \\
\hline & Divorced/widowed/etc. & 2.0 & 2.4 & 1.5 & 0.0 \\
\hline & Pct. with work hours change of & & & & \\
\hline & +20 hours or greater & 3.6 & 8.4 & 1.2 & 5.0 \\
\hline & -20 hours or greater & 2.9 & 4.3 & 1.2 & 0.0 \\
\hline \multirow[t]{7}{*}{$\overline{1980-81}$} & Pct. moved in past year & 15.9 & 18.6 & 13.3 & 11.5 \\
\hline & Pct. with marital changes & & & & \\
\hline & Married & 1.4 & 2.4 & 1.1 & 1.9 \\
\hline & Divorced/widowed/etc. & 1.5 & 2.0 & 1.3 & 0.0 \\
\hline & Pct. with work hours change of & & & & \\
\hline & +20 hours or greater & 5.3 & 8.1 & 3.5 & 1.9 \\
\hline & -20 hours or greater & 3.6 & 7.2 & 0.4 & 0.0 \\
\hline \multirow[t]{7}{*}{$\overline{1981-82}$} & Pct. moved in past year & 17.3 & 18.1 & 13.5 & 11.0 \\
\hline & Pct. with marital changes & & & & \\
\hline & Married & 1.8 & 1.4 & 1.1 & 1.2 \\
\hline & Divorced/widowed/etc. & 1.8 & 2.2 & 1.2 & 2.4 \\
\hline & Pct. with work hours change of & & & & \\
\hline & +20 hours or greater & 5.8 & 9.9 & 3.3 & 7.3 \\
\hline & -20 hours or greater & 4.8 & 6.6 & 1.9 & 1.2 \\
\hline \multirow[t]{7}{*}{$\overline{1982-83}$} & Pct. moved in past year & 16.1 & 18.3 & 13.0 & 16.3 \\
\hline & Pct. with marital changes & & & & \\
\hline & Married & 1.9 & 1.6 & 1.5 & 2.9 \\
\hline & Divorced/widowed/etc. & 2.7 & 2.5 & 1.4 & 1.0 \\
\hline & Pct. with work hours change of & & & & \\
\hline & +20 hours or greater & 4.8 & 6.9 & 2.9 & 5.8 \\
\hline & -20 hours or greater & 5.8 & 8.7 & 1.2 & 1.9 \\
\hline \multirow[t]{7}{*}{$\overline{1983-84}$} & Pct. moved in past year & 18.8 & 18.9 & 14.8 & 14.8 \\
\hline & Pct. with marital changes: & & & & \\
\hline & Married & 1.5 & 1.9 & 1.8 & 2.3 \\
\hline & Divorced/widowed/etc. & 2.2 & 2.3 & 2.1 & 2.3 \\
\hline & Pct. with work hours change of & & & & \\
\hline & +20 hours or greater & 4.0 & 5.3 & 2.1 & 4.7 \\
\hline & -20 hours or greater & 5.9 & 8.1 & 0.7 & 1.6 \\
\hline \multirow[t]{6}{*}{$\overline{1984-85}$} & Pct. moved in past year & 20.2 & 22.1 & 16.1 & 18.2 \\
\hline & Pct. with marital changes & & & & \\
\hline & Married & 2.3 & 2.7 & 2.5 & 3.0 \\
\hline & Divorced/widowed/etc. & 2.3 & 1.9 & 2.2 & 1.2 \\
\hline & Pct. with work hours change of & & & & \\
\hline & -20 hours or greater & $\begin{array}{l}4.4 \\
4.1\end{array}$ & $\begin{array}{l}1.3 \\
7.8\end{array}$ & $\begin{array}{l}2.5 \\
1.7\end{array}$ & $\begin{array}{l}4.8 \\
3.0\end{array}$ \\
\hline
\end{tabular}




\begin{tabular}{|c|c|c|c|c|c|}
\hline Interval & Variable & White & Black & White & Black \\
\hline \multirow[t]{7}{*}{$\overline{1979-82}$} & Pct. moved in any of past 3 years & 32.1 & 33.4 & 25.8 & 22.5 \\
\hline & \multicolumn{5}{|c|}{ Pct. with marital changes in any of past 3 years } \\
\hline & Married & 4.8 & 6.1 & 4.1 & 5.0 \\
\hline & Divorced/widowed/etc. & 4.8 & 4.5 & 4.6 & 0.0 \\
\hline & \multicolumn{5}{|c|}{ Pct. with work hours change of __ in any of past 3 years } \\
\hline & +20 hours or greater & 13.0 & 21.9 & 7.8 & 12.5 \\
\hline & -20 hours or greater & 16.2 & 20.2 & 14.2 & 7.5 \\
\hline \multirow[t]{7}{*}{$\overline{1980-83}$} & Pct. moved in any of past 3 years & 30.8 & 33.9 & 25.2 & 26.9 \\
\hline & \multicolumn{5}{|c|}{ Pct. with marital changes in any of past 3 years } \\
\hline & Married & 4.6 & 5.6 & 3.4 & 7.7 \\
\hline & Divorced/widowed/etc. & 4.6 & 4.5 & 3.8 & 3.8 \\
\hline & \multicolumn{5}{|c|}{ Pct. with work hours change of __ in any of past 3 years } \\
\hline & +20 hours or greater & 14.0 & 21.5 & 8.7 & 15.4 \\
\hline & -20 hours or greater & 19.1 & 23.8 & 16.9 & 17.3 \\
\hline \multirow[t]{7}{*}{$\overline{1981-84}$} & Pct. moved in any of past 3 years & 31.1 & 33.6 & 28.9 & 27.1 \\
\hline & \multicolumn{5}{|c|}{ Pct. with marital changes in any of past 3 years } \\
\hline & Married & 5.4 & 5.8 & 4.7 & 5.9 \\
\hline & Divorced/widowed/etc. & 4.8 & 4.3 & 3.7 & 4.7 \\
\hline & \multicolumn{5}{|c|}{ Pct. with work hours change of _ in any of past 3 years } \\
\hline & +20 hours or greater & 13.6 & 19.7 & 8.8 & 17.6 \\
\hline & -20 hours or greater & 19.5 & 23.2 & 15.2 & 20.0 \\
\hline \multirow[t]{7}{*}{$\overline{1982-85}$} & Pct. moved in any of past 3 years & 34.0 & 37.1 & 31.2 & 32.4 \\
\hline & \multicolumn{5}{|c|}{ Pct. with marital changes in any of past 3 years } \\
\hline & Married & 6.7 & 6.6 & 5.5 & 4.8 \\
\hline & Divorced/widowed/etc. & 5.5 & 5.7 & 5.1 & 6.7 \\
\hline & \multicolumn{5}{|c|}{ Pct. with work hours change of __ in any of past 3 years } \\
\hline & +20 hours or greater & 11.6 & 17.8 & 7.4 & 14.3 \\
\hline & -20 hours or greater & 19.4 & 24.0 & 14.0 & 14.3 \\
\hline \multirow[t]{7}{*}{$\overline{1979-84}$} & Pct. moved in any of past 5 years & 39.7 & $\overline{41.7}$ & 34.5 & 30.0 \\
\hline & \multicolumn{5}{|c|}{ Pct. with marital changes in any of past 5 years } \\
\hline & Married & 7.5 & 8.7 & 7.0 & 5.0 \\
\hline & Divorced/widowed/etc. & 7.1 & 6.7 & 7.8 & 2.5 \\
\hline & \multicolumn{5}{|c|}{ Pct. with work hours change of _ in any of past 5 years } \\
\hline & +20 hours or greater & 19.1 & 29.1 & 11.9 & 20.0 \\
\hline & -20 hours or greater & 29.0 & 32.0 & 25.8 & 20.0 \\
\hline \multirow[t]{7}{*}{$\overline{1980-85}$} & Pct. moved in any of past 5 years & 40.6 & 44.4 & 36.4 & 36.5 \\
\hline & \multicolumn{5}{|c|}{ Pct. with marital changes in any of past 5 years } \\
\hline & Married & 7.9 & 8.3 & 6.6 & 9.6 \\
\hline & Divorced/widowed/etc. & 7.7 & 8.1 & 6.8 & 7.7 \\
\hline & \multicolumn{5}{|c|}{ Pct. with work hours change of __ in any of past 5 years } \\
\hline & +20 hours or greater & 19.3 & 28.0 & 12.3 & 19.2 \\
\hline & -20 hours or greater & 30.1 & 34.8 & 26.7 & 28.8 \\
\hline
\end{tabular}




\section{Appendix D. Sample Selection Effects}

The PSID also indicates whether a household held a mortgage during the survey year, which allows for an assessment of whether the mortgage-holder sample differs from the general population regarding earnings instability and risk. The data thus offers an opportunity to gain insights regarding the nature of the selection process for obtaining mortgages and its implications for risks associated with earnings instability. Given that the population of mortgage applicants and, by extension, mortgage holders is not randomly selected from the general population, the relationship between earnings stability and race might be systematically different for these households relative to the overall population. All analyses are thus conducted using a subsample of mortgage holders to determine whether patterns for this sample differ significantly from those of the sample at large. If so, this would support the notion that selection mechanisms play an important role in observed patterns of mortgage lending approvals. Such mechanisms might operate through the manner by which individuals decide to apply for mortgages or via the manner in which lenders approve applications.

The comparative analysis of earnings profiles using the mortgage holder subsample yields the same qualitative results as before. Whites in the sample still have larger average earnings growth, but this disparity is again insignificant after controlling for differences in individual

characteristics (Table D.1). Table D.2 shows sample statistics measuring the dispersion of $\frac{\varepsilon_{t}}{P_{t+i}}$, as defined in equation (2). Once again, the results indicate that the residual is an important component of overall growth (first two columns) and whites in the sample have larger standard deviations. However, unlike in the overall sample, no clear pattern emerges using the variation ratio, while the interquartile range is larger for whites. Among mortgage holders, then, earnings dispersion is wider for whites than for comparable blacks once extreme values are excluded. Otherwise, few consistent racial differences are evident.

Turning to drastic earnings shocks, the results of estimating equation (3) are shown in Table D.3. Blacks are neither consistently more nor consistently less likely to experience catastrophes or boons. In sharp contrast to the results using the overall sample, point estimates suggest no racial differences exist in the incidence of drastic earnings shocks. Also, parameter estimates for the mortgage holder subsample have lower levels of statistical significance, particularly for catastrophes. Further, both the average shock and persistence of drastic shock estimates show 
similar effects. The black-white gap is smaller and statistical significance of parameters is weaker in the mortgage holder subsample than in the full sample.

Taken together, these results suggest that sample selection does play a role in mortgage lending. Differences between blacks and whites are reduced in the sample of mortgage holders. However, racial differences in earnings stability remain relatively small. 
Table D.1. Unconditional Means of Earnings Changes and Regression Estimates, Mortgage holders only

\begin{tabular}{|c|c|c|c|c|c|}
\hline \multirow{2}{*}{ Interval } & \multicolumn{2}{|c|}{$\begin{array}{l}\text { Unconditional } \\
\text { Mean }\end{array}$} & \multicolumn{3}{|c|}{ Regression Results } \\
\hline & White & Black & $\begin{array}{c}\text { Race } \\
\text { Coefficient }\end{array}$ & $\mathrm{t}$ & $\mathrm{R}^{2}$ \\
\hline 1979-82 & 0.216 & 0.182 & 0.028 & 0.19 & 0.163 \\
\hline $1980-83$ & 0.174 & 0.158 & 0.066 & 0.53 & 0.146 \\
\hline 1981-84 & 0.202 & 0.028 & -0.077 & -0.74 & 0.090 \\
\hline $1982-85$ & -- & -- & --- & --- & --- \\
\hline $1983-86$ & 0.177 & 0.072 & -0.079 & -0.89 & 0.073 \\
\hline 1984-87 & 0.118 & 0.165 & 0.031 & 0.36 & 0.067 \\
\hline $1985-88$ & 0.101 & -0.018 & -0.105 & -1.57 & 0.036 \\
\hline 1979-84 & 0.380 & 0.208 & -0.101 & -0.51 & 0.180 \\
\hline $1980-85$ & 0.329 & 0.184 & -0.020 & -0.11 & 0.138 \\
\hline $1981-86$ & 0.320 & 0.028 & -0.181 & -1.44 & 0.123 \\
\hline $1982-87$ & -- & -- & --- & --- & --- \\
\hline $1983-88$ & 0.270 & 0.119 & -0.113 & -0.99 & 0.098 \\
\hline
\end{tabular}

NOTE: Significant coefficients at 5\% are bold with asterisks $(*)$. Significant coefficients at $10 \%$ have $\operatorname{carats}\left({ }^{\wedge}\right)$. Regressions also include dummies for experience, tenure, education, region, selfemployment status, union status, and marital status. Intervals beginning in 1982 are omitted because the PSID did not obtain mortgage information for that year. 
Table D.2. Selected sample statistics for $\frac{\varepsilon_{t}}{P_{t+i}}$, by race, Mortgage holders only

\begin{tabular}{|c||c|c|c|c|c|c||c|c|}
\hline \multicolumn{1}{|c||}{ Interval } & \multicolumn{2}{|c|}{ Mean } & \multicolumn{2}{c||}{ Standard Dev. } & \multicolumn{2}{c|}{ Var. Ratio } & \multicolumn{2}{c|}{$\begin{array}{c}\text { Interquartile } \\
\text { Range }\end{array}$} \\
\hline & White & Black & White & Black & White & Black & White & Black \\
\hline $1979-82$ & 0.502 & 0.049 & 2.309 & 0.522 & 0.217 & 0.094 & 1.002 & 0.998 \\
\hline $1980-83$ & 0.593 & 0.002 & 6.019 & 0.741 & 0.099 & 0.002 & 1.064 & 0.822 \\
\hline $1981-84$ & 0.594 & 0.739 & 5.522 & 0.649 & 0.108 & 1.138 & 1.174 & 0.815 \\
\hline $1982-85$ & -- & -- & -- & -- & -- & -- & -- & -- \\
\hline $1983-86$ & 0.293 & 0.235 & 3.004 & 5.758 & 0.097 & 0.041 & 0.954 & 1.251 \\
\hline $1984-87$ & 0.908 & 0.307 & 5.951 & 0.907 & 0.153 & 0.339 & 0.955 & 1.048 \\
\hline $1985-88$ & 0.252 & 0.587 & 13.862 & 2.908 & 0.018 & 0.202 & 0.996 & 1.011 \\
\hline & & & & & & & & \\
\hline $1979-84$ & -0.004 & 0.041 & 3.556 & 0.550 & -0.001 & 0.075 & 1.110 & 0.879 \\
\hline $1980-85$ & 0.229 & -0.086 & 2.927 & 0.738 & 0.078 & -0.117 & 0.913 & 1.464 \\
\hline $1981-86$ & 0.248 & 0.343 & 6.600 & 1.275 & 0.038 & 0.269 & 1.138 & 1.350 \\
\hline $1982-87$ & -- & -- & -- & -- & -- & -- & -- & -- \\
\hline $1983-88$ & 0.239 & 0.085 & 6.652 & 2.929 & 0.036 & 0.029 & 0.920 & 1.068 \\
\hline
\end{tabular}

NOTE: Observations with exceptional growth, defined as growth greater than 300 percent, are omitted. There are 9 such observations, cumulatively. Intervals beginning in 1982 are omitted because the PSID did not obtain mortgage information for that year. 


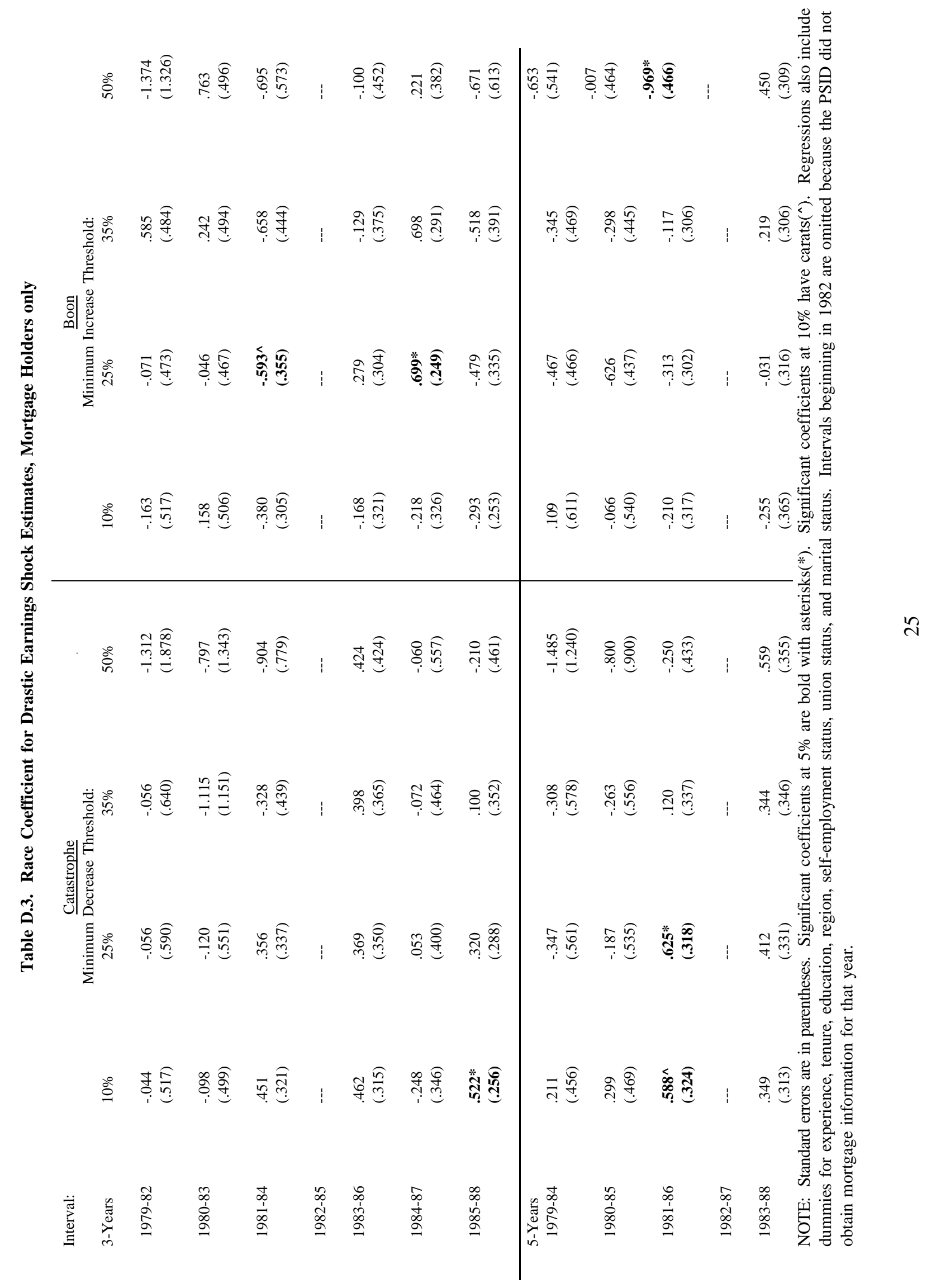




\section{REFERENCES}

Benston, G.J. (1995), "The History and Value of HMDA Data for Studies of Invidious Discrimination," in Fair Lending Analysis: A Compendium of Essays on the Use of Statistics, A.M. Yezer (Ed.), American Bankers Association, Washington.

Berkovec, J.A., G.B Canner, S.A. Gabriel, and T.H. Hannan (1994), "Race, Redlining, and Residential Mortgage Loan Performance," Journal of Real Estate Finance and Economics, 9, 263-294.

Bostic, R.W. (1997), "The Role of Race in Mortgage Lending: Revisiting the Boston Fed Study," Board of Governors of the Federal Reserve System, Finance and Economics Discussion Series Working Paper No. 1997-2.

Bound, J. and R.B. Freeman (1992), "What Went Wrong? The Erosion of Relative Earnings and Employment among Young Black Men in the 1980s," Quarterly Journal of Economics, 107(1), 201-232.

Carroll, C. (1991), "Buffer Stock Saving and the Permanent Income Hypothesis," Board of Governors of the Federal Reserve System, Economic Activity Section Working Paper No. 114.

Deaton, A. (1991), "Saving and Liquidity Constraints, Econometrica, 59, 1121-1142.

Friedman, M. (1957), A Theory of the Consumption Function, Princeton University Press, Princeton.

Gottschalk, P. (1982), "Earnings Mobility: Permanent Change or Transitory Fluctuations?," Review of Economics and Statistics, 64(3), 450-56.

Hunter, W.C. and M.B. Walker (1996), "The Cultural Affinity Hypothesis and Mortgage Lending Decisions," Journal of Real Estate Finance and Economics, 13(1), 57-70.

Lillard, L.A. and R.J. Willis (1986), "Dynamic Aspects of Earning Mobility," Econometrica, 46(5), 985-1012.

Munnell, A.H., G.M. Tootell, L.E. Browne, and J. McEneaney (1996), "Mortgage Lendingin Boston: Interpreting HMDA Data," American Economic Review, 86(1).

Ong, P.M. and J.R. Lawrence (1995), "Race and Employment Dislocation in California's Aerospace Industry," Review of Black Political Economy, 23(3), 91-101. 
Table 1. Selected Estimates from Munnell, et al. (1996): Equations with Race Run Interactively with All Variables

Logit Estimate

Interactive Term:

Housing expense/income

$0.16(0.34)$

Total debt payments/tincome

$0.05(1.99)$

Net wealth

$-0.0004(-0.74)$

Consumer credit history

$-0.02(-0.19)$

Mortgage credit history

$0.26(0.59)$

Public record history

$-0.10(-0.16)$

Unemployment region

$0.03(0.30)$

Self-employed

$-1.43(-2.00)$

Loan/appraised value-low

$-0.93(-0.48)$

Loan/appraised value-medium

$-1.61(-1.02)$

Loan/appraised value-high

$-1.08(-0.80)$

Denied private mortgage insurance

$-1.67(-1.17)$

Two- to four-family home

$-0.44(-0.85)$

Number of observations

2925

NOTE: Numbers in parentheses are t-statistics.

Source: Munnell, et. al (1996), American Economic Review, 86(1), p. 50. 
Table 2. The Relation between Earnings Variation and Default and Prepayment

\begin{tabular}{|c|c|c|}
\hline Source of Variation & Default & $\begin{array}{c}\text { Prepayment } \\
\text { (refi.,personal) }\end{array}$ \\
\hline Upside Variation & - & $0,+$ \\
\hline Downside Variation & + &,-+ \\
\hline Net Effect & $?$ & $?$ if refinance is feasible \\
& + if no refinance likely \\
\hline
\end{tabular}


Table 3. Unconditional Means of Earnings Changes and Regression Estimates

\begin{tabular}{|c|c|c|c|c|c|}
\hline \multirow{2}{*}{ Interval } & \multicolumn{2}{|c|}{$\begin{array}{l}\text { Unconditional } \\
\text { Mean }\end{array}$} & \multicolumn{3}{|c|}{ Regression Results } \\
\hline & $\begin{array}{l}\text { Whit } \\
\text { e }\end{array}$ & Black & $\begin{array}{c}\text { Race } \\
\text { Coefficient }\end{array}$ & $\mathrm{t}$ & $\mathrm{R}^{2}$ \\
\hline 1979-82 & 0.206 & 0.150 & 0.011 & 0.100 & 0.157 \\
\hline $1980-83$ & 0.162 & 0.082 & -0.022 & -0.217 & 0.103 \\
\hline $1981-84$ & 0.183 & 0.051 & -0.097 & 1.170 & 0.087 \\
\hline $1982-85$ & 0.170 & 0.042 & -0.130 & -1.570 & 0.920 \\
\hline $1983-86$ & 0.161 & 0.050 & -0.107 & -1.510 & 0.084 \\
\hline $1984-87$ & 0.106 & 0.100 & -0.022 & -0.358 & 0.064 \\
\hline $1985-88$ & 0.088 & 0.008 & -0.073 & -1.603 & 0.056 \\
\hline 1979-84 & 0.369 & 0.091 & -0.207 & -1.290 & 0.175 \\
\hline $1980-85$ & 0.310 & 0.213 & -0.049 & -0.325 & 0.135 \\
\hline 1981-86 & 0.275 & 0.089 & $-0.177^{\wedge}$ & -1.750 & 0.111 \\
\hline $1982-87$ & 0.255 & 0.060 & $-0.221^{*}$ & -2.070 & 0.143 \\
\hline $1983-88$ & 0.255 & 0.130 & -0.121 & -1.310 & 0.122 \\
\hline
\end{tabular}

NOTE: Significant coefficients at $5 \%$ are bold with asterisks(*). Significant coefficients at $10 \%$ have $\operatorname{carats}\left({ }^{\wedge}\right)$. Regressions also include dummies for experience, tenure, education, region, self-employment status, union status, and marital status. 
Table 4. Percentage Earnings Changes, means and measures of variation

\begin{tabular}{|c|c|c|c|c|c|c|}
\hline \multirow{2}{*}{ Interval } & \multicolumn{2}{|c|}{ Trend } & \multicolumn{2}{c|}{ Standard Dev. } & \multicolumn{2}{c|}{ Var. Ratio } \\
\cline { 2 - 7 } & White & Black & White & Black & White & Black \\
\hline $1979-82$ & 0.206 & 0.150 & 0.424 & 0.269 & 0.486 & 0.558 \\
\hline $1980-83$ & 0.162 & 0.082 & 0.393 & 0.336 & 0.412 & 0.244 \\
\hline $1981-84$ & 0.183 & 0.051 & 0.444 & 0.323 & 0.412 & 0.158 \\
\hline $1982-85$ & 0.170 & 0.042 & 0.416 & 0.348 & 0.409 & 0.121 \\
\hline $1983-86$ & 0.161 & 0.050 & 0.39 & 0.473 & 0.413 & 0.106 \\
\hline $1984-87$ & 0.106 & 0.100 & 0.387 & 0.297 & 0.274 & 0.337 \\
\hline $1985-88$ & 0.088 & 0.008 & 0.339 & 0.274 & 0.260 & 0.029 \\
\hline & & & & & & 0.49 \\
\hline $1979-84$ & 0.369 & 0.091 & 0.593 & 0.441 & 0.622 & 0.206 \\
\hline $1980-85$ & 0.310 & 0.213 & 0.582 & 0.528 & 0.533 & 0.403 \\
\hline $1981-86$ & 0.275 & 0.089 & 0.546 & 0.53 & 0.504 & 0.168 \\
\hline $1982-87$ & 0.255 & 0.060 & 0.548 & 0.518 & 0.465 & 0.116 \\
\hline $1983-88$ & 0.255 & 0.130 & 0.528 & 0.455 & 0.483 & 0.286 \\
\hline
\end{tabular}

NOTE: Observations with exceptional growth, defined as growth greater than 300 percent, are omitted. There are 15 such observations, cumulatively. 
Table 5. Selected sample statistics for $\frac{\varepsilon}{\boldsymbol{P}_{t+i}}$, by race

\begin{tabular}{|c||c|c|c|c|c|c||c|c|}
\hline \multicolumn{1}{|c||}{ Interval } & \multicolumn{3}{|c|}{ Mean } & \multicolumn{2}{c||}{ Standard Dev. } & \multicolumn{2}{c|}{$\begin{array}{c}\text { Var. Ratio } \\
\text { Range }\end{array}$} \\
\hline \multicolumn{1}{|c||}{ White } & Black & White & Black & White & Black & White & Black \\
\hline $1979-82$ & 0.365 & 0.626 & 2.361 & 1.092 & 0.155 & 0.210 & 0.970 & 1.034 \\
\hline $1980-83$ & 0.637 & -0.058 & 5.201 & 1.148 & 0.122 & -0.051 & 0.970 & 0.832 \\
\hline $1981-84$ & 0.575 & 0.588 & 4.360 & 1.077 & 0.132 & 0.546 & 1.066 & 1.246 \\
\hline $1982-85$ & 0.533 & 0.878 & 4.976 & 3.829 & 0.107 & 0.229 & 0.994 & 1.174 \\
\hline $1983-86$ & 0.512 & 0.012 & 4.475 & 6.616 & 0.114 & 0.002 & 1.044 & 1.807 \\
\hline $1984-87$ & 0.248 & 1.051 & 14.881 & 2.422 & 0.017 & 0.434 & 0.894 & 0.941 \\
\hline $1985-88$ & 0.381 & 0.465 & 9.762 & 2.775 & 0.039 & 0.168 & 1.009 & 0.946 \\
\hline & & & & & & & & \\
\hline $1979-84$ & 0.471 & 0.442 & 6.780 & 1.179 & 0.069 & 0.375 & 1.054 & 1.334 \\
\hline $1980-85$ & 0.305 & 0.223 & 2.752 & 1.155 & 0.111 & 0.193 & 1.027 & 1.247 \\
\hline $1981-86$ & 1.919 & 0.545 & 33.026 & 1.073 & 0.058 & 0.508 & 1.063 & 1.320 \\
\hline $1982-87$ & 0.267 & 0.374 & 5.757 & 1.972 & 0.046 & 0.190 & 0.930 & 1.202 \\
\hline $1983-88$ & 0.346 & 0.243 & 6.252 & 2.685 & 0.055 & 0.091 & 0.984 & 1.344 \\
\hline
\end{tabular}

NOTE: Observations with exceptional growth, defined as growth greater than 300 percent, are omitted. There are 15 such observations, cumulatively. 


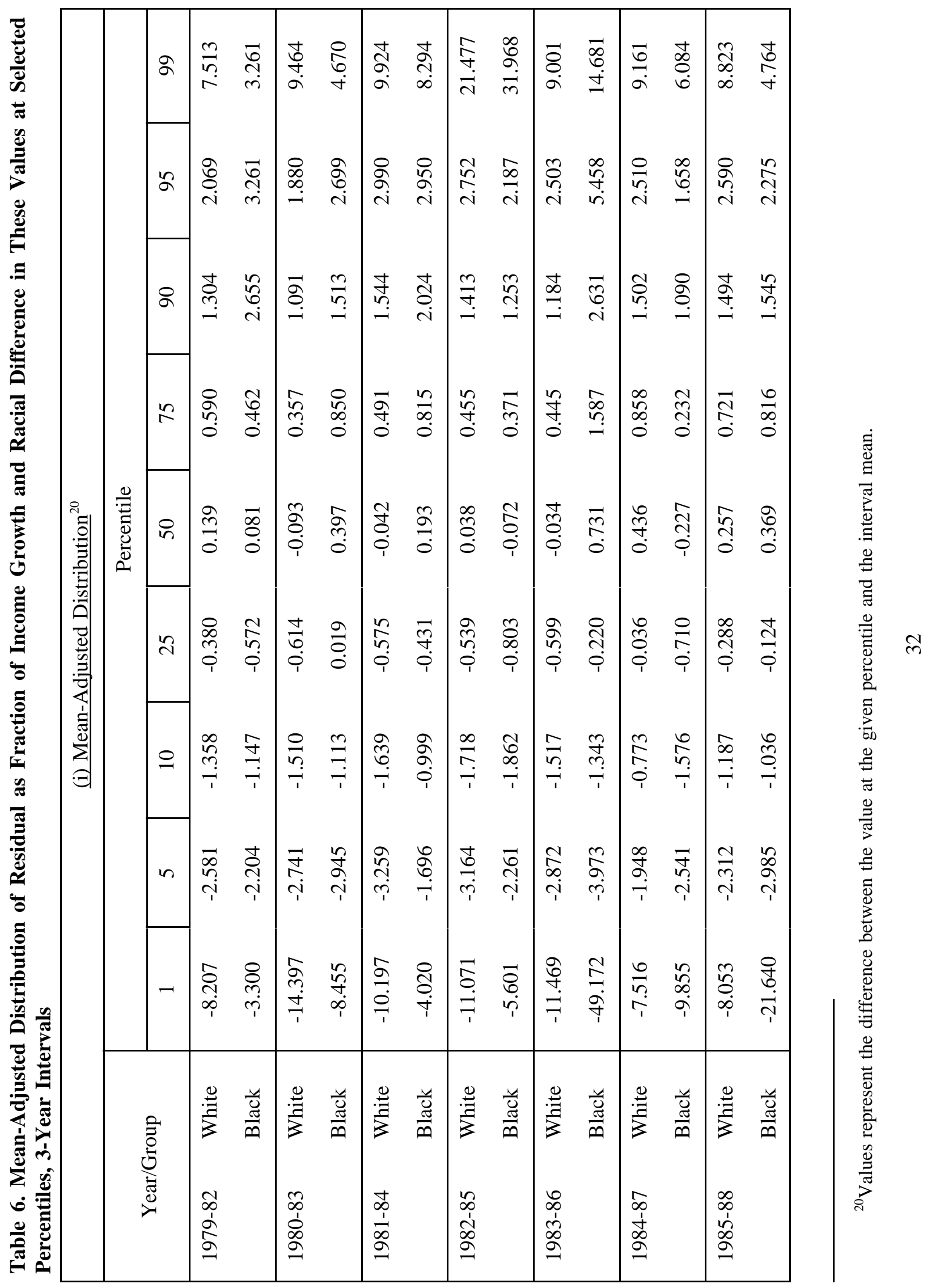



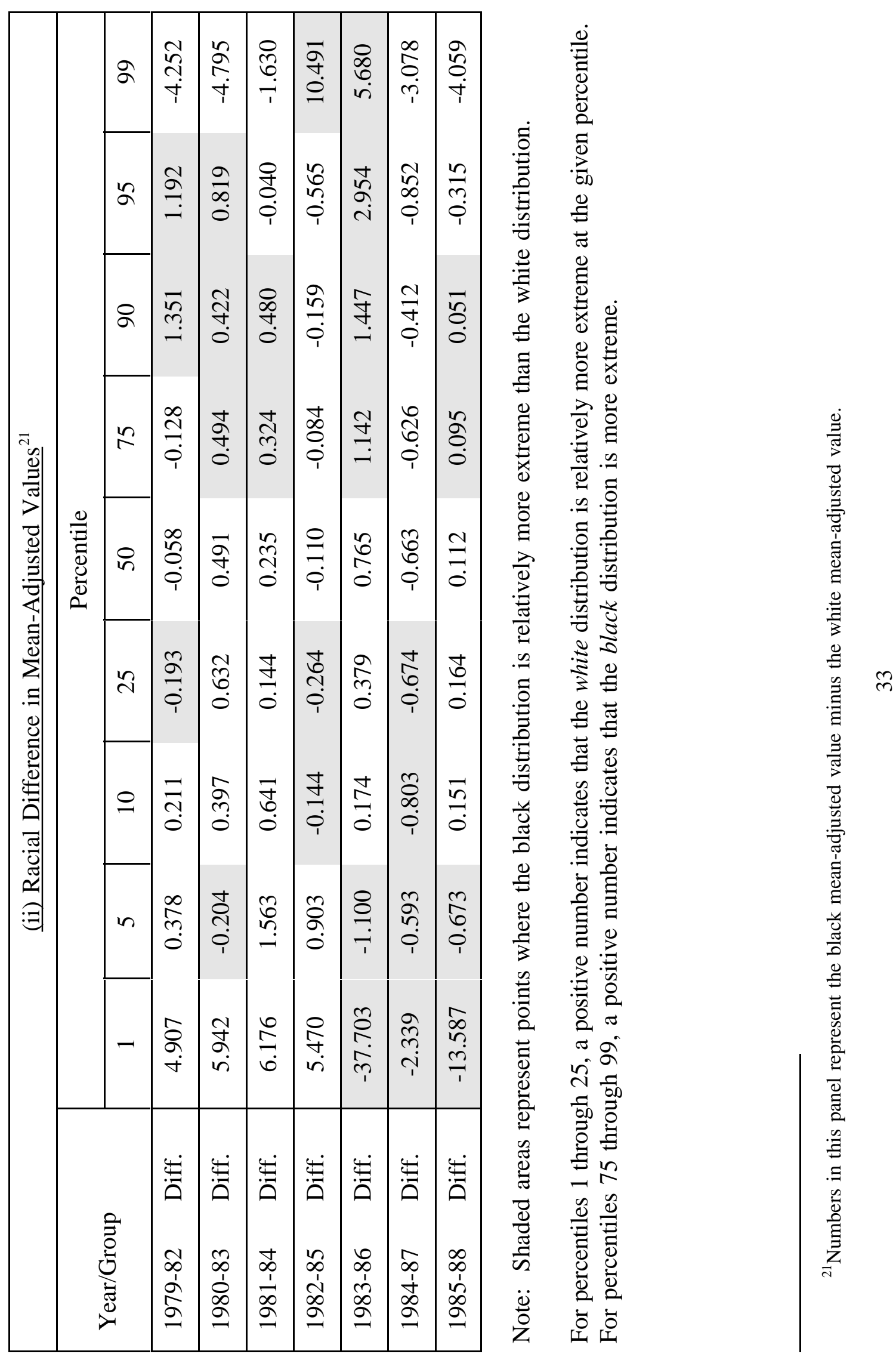


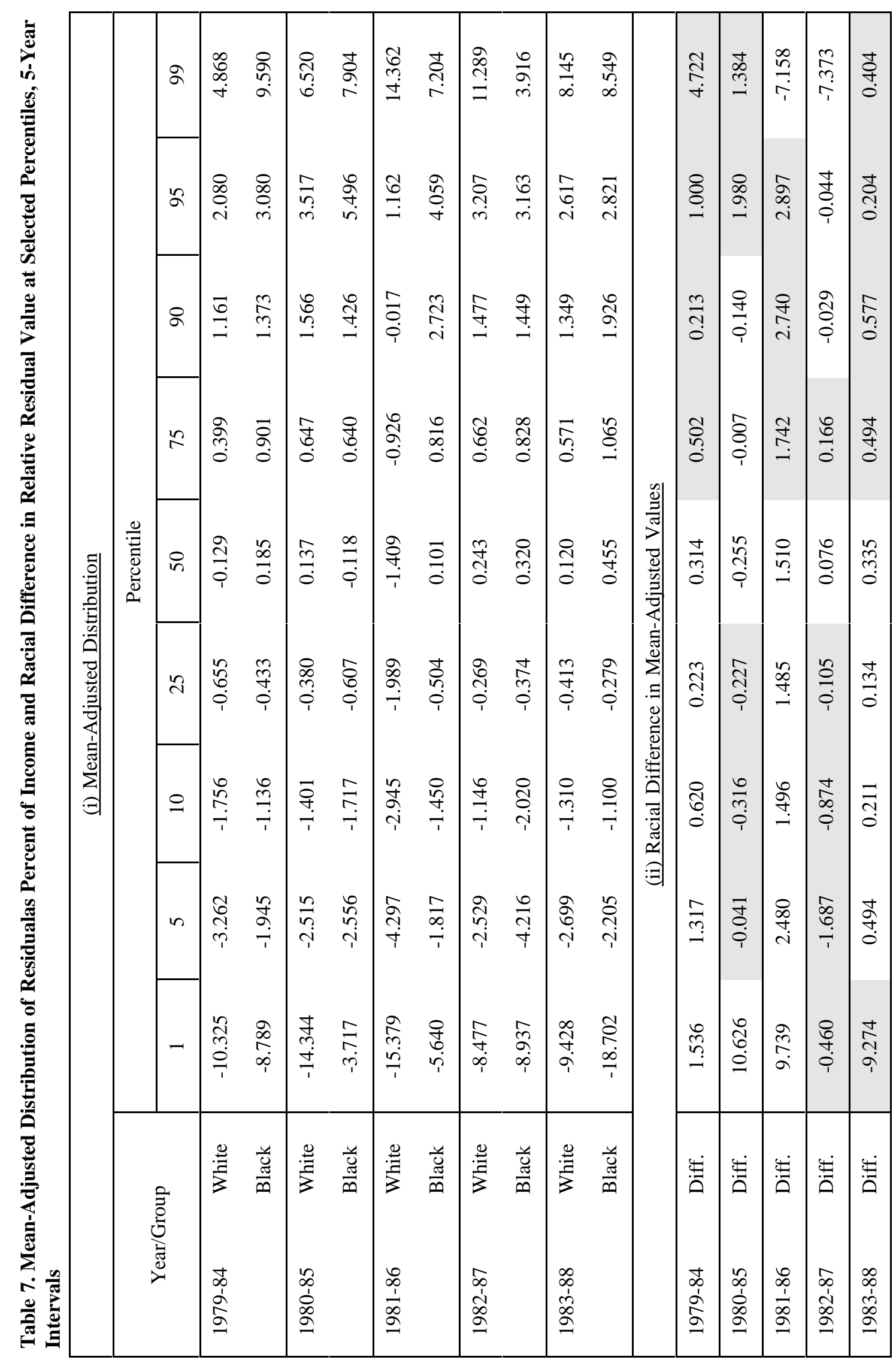




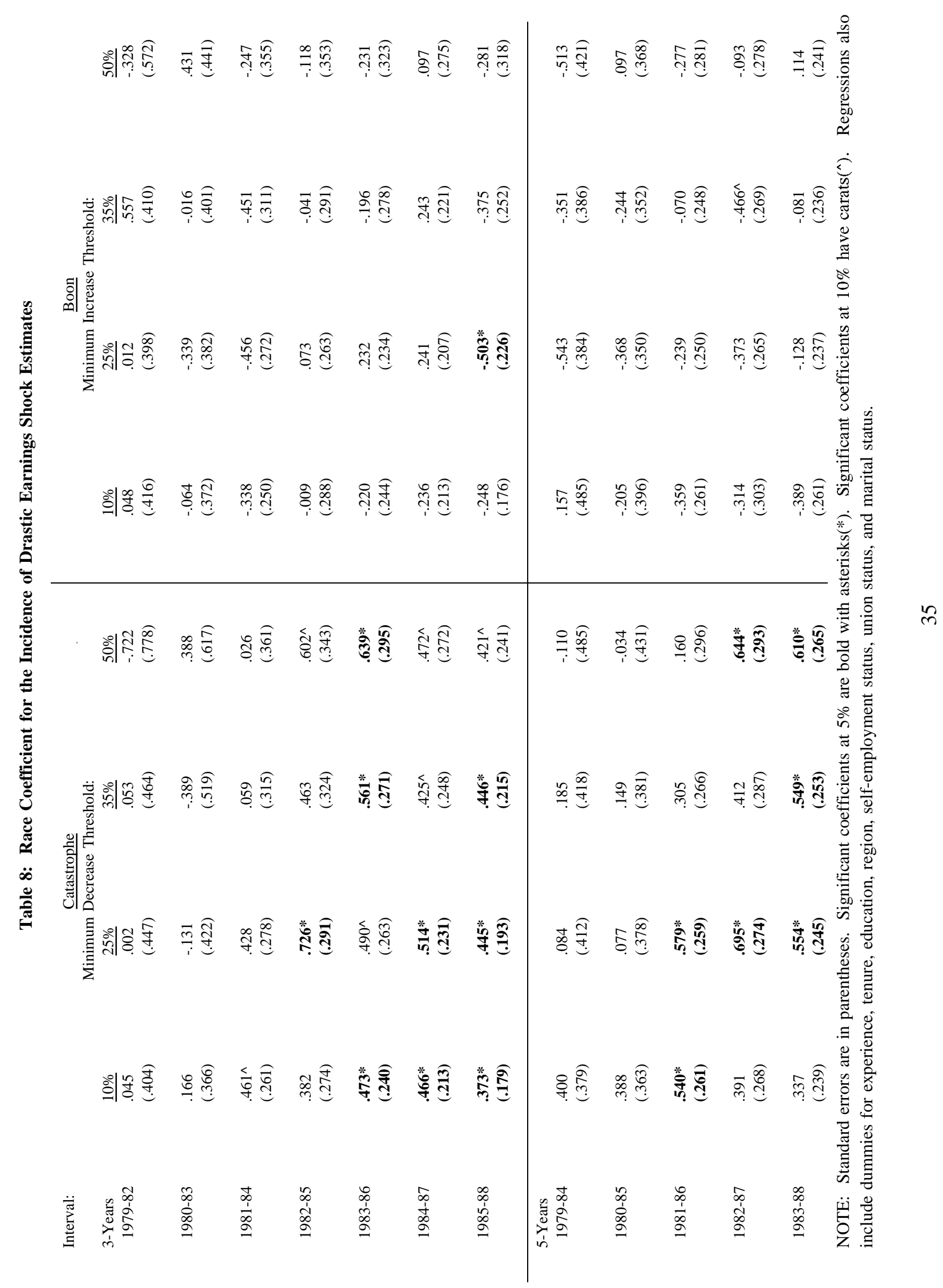


Table 9. Race Coefficient for Average Shock Estimates

$\begin{array}{llll}\text { Interval } & & \underline{\text { Race }} & \underline{\text { R-squared }} \\ \text { 3-Years } & 1979-82 & .024(.089) & .148 \\ & 1980-83 & .032(.070) & .109 \\ & 1981-84 & -.072(.053) & .101 \\ & 1982-85 & -.121(.058)^{*} & .094 \\ 1983-86 & -.076(.054) & .094 \\ & 1984-87 & -.029(.044) & .058 \\ & 1985-88 & -.070(.038)^{\wedge} & .068 \\ & & & .207 \\ & 1979-84 & -.035(.092) & .141 \\ & 1980-85 & -.007(.083) & .137 \\ 1981-86 & -.093(.060) & .118 \\ 1982-87 & -.149(.065)^{*} & .133 \\ 1983-88 & -.093(.057)^{\wedge} & \end{array}$

NOTE: Standard errors are in parentheses. Significant coefficients at 5\% are bold with asterisks(*). Significant coefficients at $10 \%$ have carats $\left(^{\wedge}\right)$. Regressions also include dummies for experience, tenure, education, region, self-employment status, union status, and marital status. 


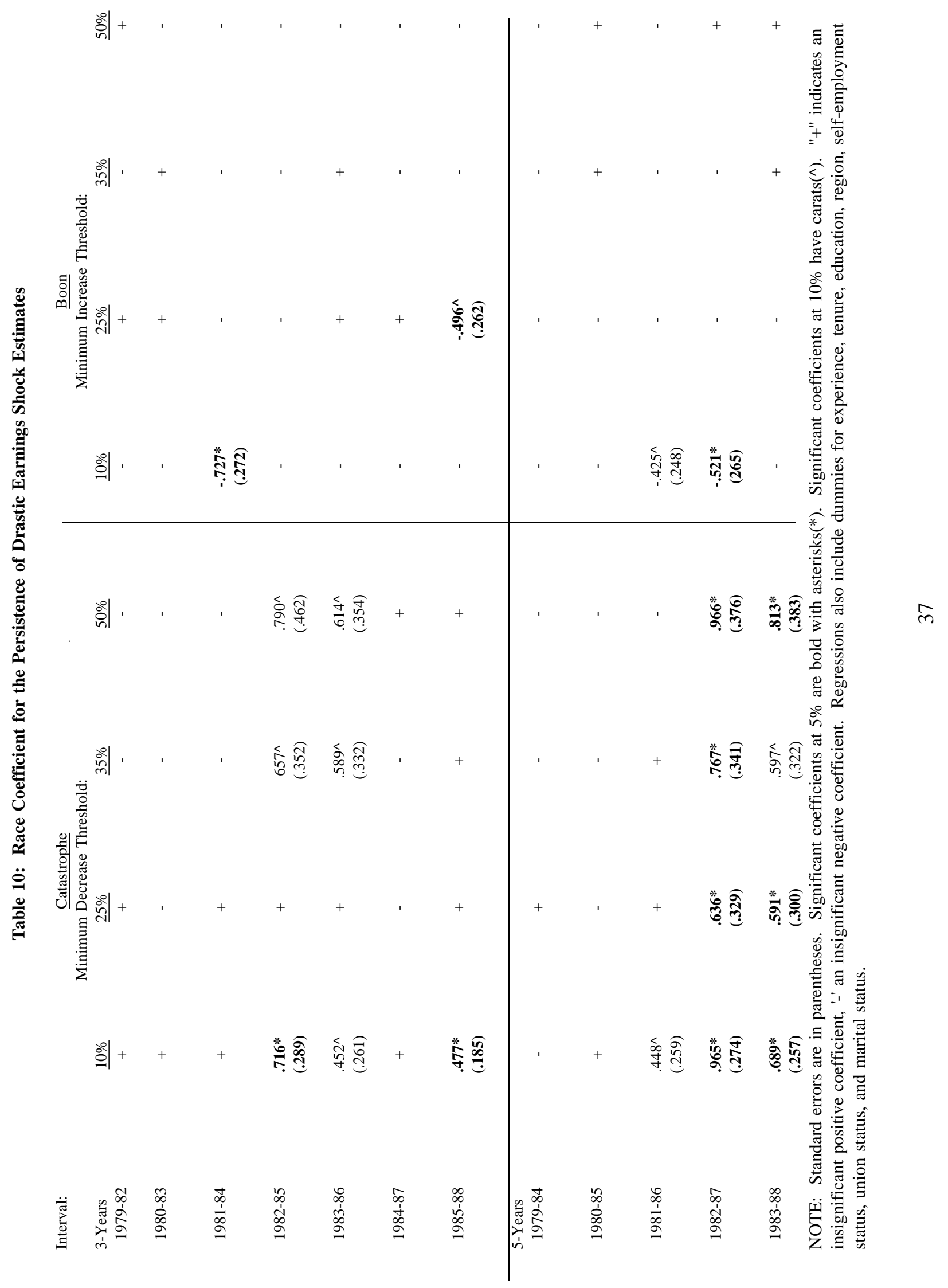




\section{Appendix A: Variables used in Estimates and Selected Sample Statistics}

\begin{tabular}{|c|c|c|c|}
\hline \multirow[b]{2}{*}{ Variable (Statistic) } & \multirow[b]{2}{*}{$\begin{array}{l}\text { Definition if included in Estimates: } \\
=1 \text { if head has }\end{array}$} & \multicolumn{2}{|c|}{ Statistic: } \\
\hline & & White Sample & Black Sample \\
\hline Income $(\$)$ & & 36299 & 32017 \\
\hline Experience (Yrs.) & & 22 & 21 \\
\hline $0-5$ (Pct.) & <omitted variable> & 2.1 & 1.2 \\
\hline 6-10 (Pct.) & total full-time experience of $6-10$ years & 9.2 & 8 \\
\hline $11-15$ (Pct.) & total full-time experience of $11-15$ years & 16.5 & 23.9 \\
\hline 16-20 (Pct.) & total full-time experience of $16-20$ years & 19 & 26.6 \\
\hline 21-25 (Pct.) & total full-time experience of $21-25$ years & 16.2 & 11.1 \\
\hline $25+$ (Pct.) & total full-time experience of $25+$ years & 36.9 & 29.2 \\
\hline Tenure (Yrs.) & & 10.2 & 11.4 \\
\hline $0-5$ (Pct.) & <omitted variable> & 38.3 & 23.9 \\
\hline 6-10 (Pct.) & current job tenure of $6-10$ years & 19.8 & 28 \\
\hline 11-15 (Pct.) & current job tenure of $11-15$ years & 16.8 & 22.3 \\
\hline 16-20 (Pct.) & current job tenure of $16-20$ years & 12.3 & 15.7 \\
\hline 21-25 (Pct.) & current job tenure of $21-25$ years & 8 & 3.4 \\
\hline $25+($ Pct. $)$ & current job tenure of $25+$ years & 6.7 & 7.9 \\
\hline Dropout (Pct.) & less than 8 years of education & 1.9 & 6.3 \\
\hline High School (Pct.) & $8-12$ years of education & 33.1 & 43.5 \\
\hline College (Pct.) & $\begin{array}{l}12+\text { years of education <omitted } \\
\text { variable> }\end{array}$ & 65 & 50.1 \\
\hline Union (Pct.) & union membership & 23 & 52.3 \\
\hline Self-empl. (Pct.) & own business & 10.7 & 1.3 \\
\hline Married (Pct.) & spouse & 87.3 & 82.9 \\
\hline Children (Avg. Num.) & & 1.3 & 1.4 \\
\hline Region 1 & primary residence in Northeast & & \\
\hline Region 2 & primary residence in North-Central & & \\
\hline Region 3 & primary residence in South & & \\
\hline Region 4 & primary residence in West <omitted var.> & & \\
\hline
\end{tabular}


Appendix B: Unexplained Earnings Percentage Changes $\left(\epsilon_{t}\right)$ : Measures of Dispersion by Race Non-Mortgage Holders Only

Whites

\begin{tabular}{|c|c|c|c|c|}
\hline 3-Years & St. Dev. & Q3 & Q1 & Q3-Q1 \\
\hline $1979-82$ & .658 & .346 & -.408 & .754 \\
\hline $1980-83$ & .713 & .346 & -.470 & .816 \\
\hline $1981-84$ & .663 & .351 & -.480 & .831 \\
\hline $1982-85$ & --- & --- & --- & --- \\
\hline $1983-86$ & .707 & .286 & -.439 & .725 \\
\hline $1984-87$ & .739 & .328 & -.384 & .712 \\
\hline $1985-88$ & .676 & .311 & -.390 & .701 \\
\hline \multicolumn{5}{|l|}{ 5-Years } \\
\hline $1979-84$ & .784 & .439 & -.571 & 1.010 \\
\hline $1980-85$ & .795 & .492 & -.507 & .999 \\
\hline $1981-86$ & .752 & .472 & -.510 & .982 \\
\hline $1982-87$ & --- & --- & --- & --- \\
\hline $1983-88$ & .840 & .449 & -.598 & 1.047 \\
\hline
\end{tabular}




\section{Appendix B (cont'd.): Unexplained Earnings Percentage Changes $\left(\epsilon_{t}\right)$ : Measures of Dispersion by Race Non-Mortgage Holders Only}

$\underline{\text { Blacks }}$

3-Years

St. Dev.

Q3 Q1

Q3-Q1

1979-82

.620

$.331-.482$

.813

$1980-83$

.640

$.367 \quad-.550$

.917

1981-84

.601

.424

$-.438$

.862

1982-85

1983-86

.680

$.366-.466$

.832

1984-87

.695

$.323-.451$

.774

1985-88

.620

$.327 \quad-.392$

.719

5-Years

1979-84

.743

$-.697$

1.182

1980-85

.738

.502

$-.533$

1.035

1981-86

.718

.493

$-.562$

1.055

1982-87

1983-88

.749

$.555 \quad-.701$

1.256

NOTE: Mortgage holders are not identified in the 1982 wave of the PSID. Thus the 1982-85 and 1982-87 intervals have can not be calculated. 